Info Artikel Diterima Mei 2017

Disetujui Agustus 2017

Dipublikasikan April 2018

\title{
ANALISIS TINGKAT PENDAPATAN USAHATANI ALPUKAT DI KELOMPOK TANI KABUPATEN SEMARANG
}

\author{
Dytanti Ilmiansi Tamalia, Siswanto Imam Santoso, Kustopo Budiraharjo \\ Program Studi Agribisnis Fakultas Peternakan dan Pertanian \\ Universitas Diponegoro Semarang \\ Email: dtamalia03@gmail.com
}

\begin{abstract}
The purpose of this research is to know the level of avocado farm income and to know the influence of production quantity, labor cost, fertilizer cost, and selling price of avocado to farmer's income in Bandungan and Sumowono District, Semarang Regency. The study was conducted from January to March 2017 in Bandungan and Sumowono Districts. The method used in this research is survey method. The method used in determining the location of the research is purposive and the sampling method using random sampling method, and the number of respondents is determined by quota of 20 farmers in Bandungan and 20 farmers in Sumowono District. The analysis used is income analysis, profitability, one sample t-test, and multiple linear regression analysis. The results showed that the average income of farmers per year amounted to $\mathrm{Rp} 32,881,705.00$, the average of profitability is $7.72 \%$, and one sample t-test showed that the significance level is 0.044 , so it can be concluded that avocado farming that is done by farmers is generate profitable income, while the result of production factors that positively affect the net income of avocado farmers is the amount of production, labor cost, and selling price of avocado. The fertilizer cost factor does not positively affect the net income of avocado farmers.

Keywords: Income, Profitability, Production quantity, Production cost, Avocado. PENDAHULUAN

Indonesia merupakan Negara yang kaya akan sumberdaya alam. Hampir semua tanaman dapat tumbuh subur di Indonesia. Salah satunya tanaman hortikultura yaitu buah alpukat. Tanaman alpukat memiliki nama latin Persea americana Mill dan merupakan tanaman pohon berkayu yang tumbuh menahun. Alpukat merupakan salah satu komoditas pertanian yang memiliki waktu panen kurang lebih enam bulan. Buah alpukat merupakan salah satu tanaman yang dapat dibudidayakan di iklim tropis dan subtropis.

Produksi buah alpukat di Indonesia dari tahun 2011 hingga 2015 fluktuatif, namun cenderung mengalami peningkatan. Berdasarkan Badan Pusat Statistik dan Direktorat Jenderal Hortikultura (2016), produksi buah alpukat tahun 2015 dengan luas panen 24.352 ha sebesar 382.537 ton, dengan tingkat pertumbuhan produksi dari tahun 2014 ke 2015 sebesar 24,48\%. Provinsi Jawa Tengah tercatat memiliki jumlah pohon alpukat sebanyak 305.515 pohon dengan hasil produksi $310.433 \mathrm{kw}$ pada tahun 2015, sedangkan Kabupaten Semarang merupakan penghasil buah alpukat utama di Jawa Tengah dengan kepemilikan pohon alpukat sebanyak 54.141 pohon dengan produksi $85.816 \mathrm{kw}$ pada Tahun 2015 .
\end{abstract}


Buah alpukat merupakan salah satu komoditas tanaman hortikultura yang memiliki nilai ekonomis tinggi. Komoditas ini merupakan salah satu komoditas buah-buahan tahunan yang diperdagangkan di dalam maupun di luar negeri. Berdasarkan Badan Pusat Statistik (2016), ekspor buah-buahan tahunan pada tahun 2015 sebanyak 585.242,8 ton dan tahun 2016 sebanyak 841.769 ton, sehingga terjadi perubahan sebesar $43,83 \%$. Ekspor alpukat tercatat sebesar $53.508 \mathrm{~kg}$ tahun 2015 dan $41.803 \mathrm{~kg}$ tahun 2016. Permintaan pasar terhadap buah alpukat cukup tinggi. Hal tersebut dapat dilihat dari jumlah import alpukat ke Indonesia. Berdasarkan Badan Pusat Statistik (2016), Indonesia melakukan import alpukat untuk mencukupi pasar sebesar $7.401 \mathrm{~kg}$ tahun 2015 dan $8.251 \mathrm{~kg}$ tahun 2016. Masyarakat mulai sadar akan pentingnya kesehatan yang dapat ditunjang dengan mengkonsumsi buah, salah satunya buah alpukat. Ditinjau dari Pusat Data dan Statistik Informasi Pertanian (2015), rata-rata konsumsi buah alpukat di tahun 2014 sebesar $0,574 \mathrm{~kg} / \mathrm{kapita} / \mathrm{tahun}$.

Usahatani alpukat merupakan usahatani yang dapat dikembangkan sehingga kebutuhan pasar dapat dipenuhi dan mendatangkan keuntungan bagi petani (Rahmawati, 2010). Berdasarkan observasi yang dilakukan, pengelolaan usahatani yang dilakukan petani belum dirinci secara baik, sehingga diperlukan pendataan yang terperinci dari semua usaha atau pengorbanan petani terhadap budidaya alpukat ini, oleh karenanya kajian pendapatan usahatani alpukat diperlukan supaya petani dapat mengetahui seberapa besar keuntungan yang didapatkan.

\section{BAHAN DAN METODE}

Metode dasar yang digunakan dalam penelitan ini adalah metode survei. Metode survei merupakan suatu metode pendekatan pengumpulan data dengan mengambil karakteristik atau ciri-ciri dari sebagian unit pengamatan yang diambil dari populasi (Asra dan Prasetyo, 2015). Menurut Singarimbun dan Effendi (1989), penelitian survei digunakan untuk penjajagan, deskriptif, penjelasan yakni menjelaskan hubungan kausal dan pengujian hipotesis, evaluasi, prediksi, penelitian operasional, dan pengembangan indikator-indikator sosial. Metode survei merupakan suatu pendekatan secara kuantitatif dan data utama yang diperoleh dari hasil wawancara.

Daerah penelitian yang diambil yaitu di Kecamatan Bandungan dan Sumowono Kabupaten Semarang Jawa Tengah. Pemilihan lokasi dilakukan secara purposive berdasarkan pertimbangan keadaan usahatani yang dilakukan secara intensif, jumlah produksi, serta merupakan daerah-daerah yang mengembangkan tanaman alpukat di Kabupaten Semarang. Kecamatan Sumowono dan Bandungan merupakan dua kecamatan yang memproduksi buah alpukat paling banyak di Kabupaten Semarang dengan total produksi Kecamatan Sumowono 17.302 Kw dan Kecamatan Bandungan $71.448 \mathrm{Kw}$.

Penentuan sampel dilakukan secara purposive sampling yaitu sampel dipilih berdasarkan ciri-ciri tertentu. Responden petani yang dipilih sebagai sampel penelitian yaitu petani yang memiliki tanaman alpukat dan sudah berproduksi, serta melakukan usahatani alpukat secara intensif. Metode pengambilan sampel dilakukan secara random sampling, yaitu secara acak 
menggunakan nomer undian. Metode penentuan jumlah responden yaitu secara kuota. Jumlah responden yaitu 20 petani Kecamatan Bandungan dan 20 petani Kecamatan Sumowono.

Data yang dikumpulkan terdiri data primer dan data sekunder. Data primer terdiri dari pendapatan, jumlah produksi, biaya produksi, harga jual alpukat, dan teknik budidaya alpukat, sedangkan data sekunder penelitian berupa data pendukung diantaranya data keadaan umum lokasi penelitian. Data primer diperoleh dari hasil wawancara langsung serta observasi peneliti di lapangan, sedangkan data sekunder diperoleh dari data kecamatan, badan pusat statistik, serta dinas pertanian.

\section{Analisis Data}

Data yang terkumpul akan dianalisis secara deskriptif kuantitatif dan secara statistik. Analisis deskriptif kuantitatif yaitu analisis yang menggambarkan suatu data secara sistematis berdasarkan data yang faktual dan akurat dalam bentuk angka, dapat berdasarkan hasil pengukuran atau hasil perhitungan (Riduwan dan Sunarto, 2012). Perhitungan biaya produksi yaitu menggunakan rumus: (Saihani, 2012).

$$
\mathrm{TC}=\mathrm{FC}+\mathrm{VC}
$$

Keterangan:

$\mathrm{TC}=$ total cost/biaya total (Rp)

$\mathrm{FC}=$ fixed cost/biaya tetap (Rp)

$\mathrm{VC}=$ variable cost/biaya variabel $(\mathrm{Rp})$

Perhitungan penerimaan/pendapatan kotor usahatani alpukat menggunakan rumus: (Saihani, 2012)

$$
\mathrm{TR}=\mathrm{Y} . \mathrm{Py}
$$

Keterangan:

$\mathrm{TR}=$ total revenue/penerimaan total $(\mathrm{Rp})$

$\mathrm{Y}=$ jumlah produksi alpukat $(\mathrm{Kg})$

Py = harga alpukat $(\mathrm{Rp})$

Perhitungan pendapatan bersih usahatani alpukat menggunakan rumus sebagai berikut: (Ekowati et al., 2014)

Keterangan:

$$
\mathrm{PB}=\mathrm{PK}-\mathrm{BU}
$$

$\mathrm{PB}=$ pendapatan bersih $(\mathrm{Rp})$

$\mathrm{PK}=$ pendapatan $\operatorname{kotor}(\mathrm{Rp})$

$\mathrm{BU}=$ biaya usaha $(\mathrm{Rp})$

Analisis profitabilitas usahatani alpukat menggunakan rumus sebagai berikut: (Ambarsari et al., 2014): 
Profitabilitas $=\frac{\text { Pendapatan bersih }}{\text { Biaya total }} \times 100 \%$

Keterangan:

Pendapatan bersih $=$ dalam rupiah

Biaya total = dalam rupiah

Analisis data secara statistik menggunakan uji one sample t-test yaitu menguji signifikansi perbedaan profitabiltas usahatani alpukat dengan nilai tes yang berupa tingkat suku bunga bank. Pengujian ini dilakukan dengan menggunakan program SPSS.

Hipotesis:

$\mathrm{H}_{0} \quad: \mu=5,5 \%$

$\mathrm{H}_{1} \quad: \mu \neq 5,5 \%$

Hipotesis kalimat :

$\mathrm{H}_{0} \quad$ = tidak ada perbedaan profitabilitas usahatani alpukat dengan suku bunga bank.

$\mathrm{H}_{1} \quad$ = ada perbedaan profitabilitas usahatani alpukat dengan suku bunga bank.

Kriteria pengujian:

Jika Signifikansi $\leq 0,05 \rightarrow \mathrm{H} 0$ ditolak, Ha diterima.

Jika Signifikansi $>0,05 \rightarrow \mathrm{H} 0$ diterima, Ha ditolak.

Analisis statistik selanjutnya yaitu analisis regresi linier berganda untuk mengetahui pengaruh jumlah produksi, biaya tenaga kerja, biaya pupuk, dan harga jual alpukat terhadap pendapatan bersih petani. Analisis statistik model analisis Regresi Linier Berganda menggunakan rumus sebagai berikut: (Sudjana, 1991)

$$
y=a+b_{1} x_{1}+b_{2} x_{2}+b_{3} x_{3}+b_{4} x_{4}+e
$$

Keterangan:

$$
\begin{array}{lll}
\mathrm{y}=\text { pendapatan petani }(\mathrm{Rp} / \text { Tahun }) & \mathrm{a} & =\text { konstanta } \\
\mathrm{x}_{1}=\text { jumlah produksi }(\mathrm{Kg} / \text { Tahun }) & \mathrm{b} & =\text { koefisien regresi } \mathrm{x} \\
\mathrm{x}_{2}=\text { biaya tenaga kerja }(\mathrm{Rp} / \text { Tahun }) & \mathrm{e} & =\text { faktor error } \\
\mathrm{x}_{3}=\text { biaya pupuk }(\mathrm{Rp} / \text { Tahun }) & & \\
\mathrm{x}_{4}=\text { harga jual }(\mathrm{Rp}) & &
\end{array}
$$

Hipotesis kalimat:

$\mathrm{H}_{0} \quad=$ tidak ada pengaruh secara serempak dan parsial jumlah produksi $\left(\mathrm{x}_{1}\right)$, biaya tenaga kerja $\left(\mathrm{x}_{2}\right)$, biaya pupuk $\left(\mathrm{x}_{3}\right)$, dan harga jual $\left(\mathrm{x}_{4}\right)$ terhadap pendapatan bersih petani.

$\mathrm{H}_{1} \quad=$ ada pengaruh secara serempak dan parsial jumlah produksi $\left(\mathrm{x}_{1}\right)$, biaya tenaga kerja $\left(\mathrm{x}_{2}\right)$, biaya pupuk $\left(\mathrm{x}_{3}\right)$, dan harga jual $\left(\mathrm{x}_{4}\right)$ terhadap pendapatan bersih petani. 


\section{Uji F (Serempak)}

Pengujian pengaruh secara serempak, variabel diuji menggunakan uji $\mathrm{F}$ dengan melihat F-hitung yang terbentuk dari persamaan sebagai berikut: (Suliyanto, 2011)

$$
\mathrm{F}=\frac{\mathrm{R}^{2} /(\mathrm{k}-1)}{1-\mathrm{R}^{2} /(\mathrm{n}-\mathrm{k})}
$$

Keterangan:

$\mathrm{F} \quad$ : nilai F hitung

$\mathrm{R}^{2} \quad$ : koefisien determinasi

$\mathrm{k} \quad$ : jumlah variabel

$\mathrm{n} \quad$ : jumlah pengamatan (ukuran sampel)

Pengujian uji serempak (uji F) dilakukan dengan menggunakan SPSS yaitu dengan melihat signifikansi dan F-hitung yang terbentuk dari output yang ditampilkan (Supranto, 2009).

Hipotesis:

$\mathrm{H}_{0} \quad: \mathrm{b} 1=\mathrm{b} 2=\mathrm{b} 3=\mathrm{b} 4=0$

$\mathrm{H}_{1} \quad: \mathrm{b} 1=\mathrm{b} 2=\mathrm{b} 3=\mathrm{b} 4 \neq 0$

Kriteria pengujian:

Jika signifikansi $\leq 0,05$ maka $\mathrm{H}_{0}$ ditolak

Jika signifikansi $>0,05$ maka $\mathrm{H}_{0}$ diterima

\section{Uji t (Parsial)}

Pengujian pengaruh secara parsial, variabel diuji menggunakan uji $t$ dengan melihat t-hitung yang terbentuk dari persamaan sebagai berikut: (Suliyanto, 2011)

$$
\mathrm{t}=\frac{\mathrm{bj}}{\mathrm{Sbj}}
$$

Keterangan:

$\mathrm{t} \quad$ : nilai t hitung

bj : koefisien regresi

Sbj : kesalahan baku

Pengujian uji parsial (uji t) dilakukan dengan menggunakan SPSS yaitu dengan melihat signifikansi dan t-hitung yang terbentuk dari output yang ditampilkan (Supranto, 2009).

Hipotesis:

$\mathrm{H}_{0} \quad: \mathrm{b} 1=0 ; \mathrm{b} 2=0 ; \mathrm{b} 3=0 ; \mathrm{b} 4=0$

$\mathrm{H}_{1} \quad: \mathrm{b} 1 \neq 0 ; \mathrm{b} 2 \neq 0 ; \mathrm{b} 3 \neq 0 ; \mathrm{b} 4 \neq 0$

Kriteria pengujian:

Jika signifikansi $\leq 0,05$ maka $\mathrm{H}_{0}$ ditolak 
Jika signifikansi > 0,05 maka $\mathrm{H}_{0}$ diterima

\section{HASIL DAN PEMBAHASAN \\ Pendapatan Usahatani Alpukat}

Pendapatan bersih merupakan hasil pengurangan penerimaan atau pendapatan kotor dengan total biaya produksi yang dikeluarkan dari suatu usaha. Pendapatan bersih ini merupakan keuntungan dari hasil usahatani alpukat yang dijalankan. Data pendapatan bersih petani dari usahatani alpukat terperinci dalam Tabel 1.

Tabel 1. Biaya Produksi, Penerimaan, dan Pendapatan Usahatani Alpukat PerTahun

\begin{tabular}{|c|c|c|c|}
\hline & Uraian & Jumlah & Persentase \\
\hline \multirow{12}{*}{ A. } & & --Rp/Tahun-- & $--\%--$ \\
\hline & Biaya Produksi & & \\
\hline & Biaya Tetap: & & \\
\hline & Penyusutan & 110.095 & 2,59 \\
\hline & $\mathrm{PBB}$ & 368.625 & 8,66 \\
\hline & Biaya Variabel: & & \\
\hline & Biaya Pupuk & 548.375 & 12,88 \\
\hline & Biaya Tenaga Kerja & 1.333 .500 & 31,32 \\
\hline & Biaya Transportasi & 1.005 .000 & 23,60 \\
\hline & Biaya Obat & 32.700 & 0,77 \\
\hline & Biaya Telepon & 860.000 & 20,20 \\
\hline & Total Biaya Produksi & 4.258 .295 & 100 \\
\hline B. & Total Penerimaan & 37.140 .000 & \\
\hline $\mathrm{C}$. & $\begin{array}{l}\text { Total Pendapatan } \\
\text { bersih }\end{array}$ & 32.881 .705 & \\
\hline D. & Profitabilitas & & 7,72 \\
\hline
\end{tabular}

Sumber: Data Primer Olahan Penelitian, 2017.

Hasil perhitungan yang dilakukan diketahui bahwa rata-rata total biaya tetap per-tahun diperoleh sebesar Rp 478.720,00, dengan persentase penyusutan $2,59 \%$ dan PBB $8,66 \%$, serta rata-rata total biaya variabel yang dikeluarkan pertahun sebesar Rp 3.779.575,00 dengan persentase biaya pupuk 12,88\%, biaya tenaga kerja $31,32 \%$, biaya transportasi $23,60 \%$, biaya obat $0,77 \%$ dan biaya telepon $20,20 \%$. Berdasarkan hasil tersebut diketahui bahwa persentase biaya variabel lebih besar dari pada biaya tetap, karena biaya variabel berhubungan langsung dengan hasil produksi atau panen yang dihasilkan. Hal tersebut sesuai dengan pendapat Lestari et al. (2011) yang dikutip dari Daniel (2002), yang menyatakan bahwa biaya variabel merupakan biaya yang besar kecilnya berhubungan langsung dengan besarnya produksi.

Rata-rata produksi per-tahun yaitu $2.397,5 \mathrm{~kg}$, harga jual pada periode satu bulan Januari - Februari Rp 8.000 - 18.000,00/kg, sedangkan periode dua bulan Juli - Agustus Rp $10.000-25.000,00 / \mathrm{kg}$. Rata-rata total penerimaan petani pertahun sebesar Rp 37.140.000,00. Rata-rata pendapatan bersih petani alpukat 
selama satu tahun yaitu sebesar Rp 32.881.705,00, pendapatan tersebut diperoleh dari hasil pendapatan kotor yaitu Rp 37.140.000,00 dikurangi dengan biaya produksi yang dikeluarkan yaitu sebesar Rp 4.258.295,00. Hal tersebut sesuai dengan pendapat Ekowati et al. (2014), yang menyatakan bahwa pendapatan usahatani merupakan selisih antara penerimaan atau pendapatan kotor dengan biaya produksi. Pendapatan yang dihasilkan petani alpukat ini lebih besar dari UMK Kabupaten Semarang. Pendapatan usahatani alpukat per-bulan yaitu sebesar Rp 2.740.142,00, sedangkan UMK Kabupaten Semarang per-bulan sebesar Rp 1.745.000,00.

Profitabilitas usahatani alpukat yang diperoleh dari membandingkan pendapatan bersih dengan biaya produksi diperoleh rata-rata profitabilitas sebesar 7,72\%. Profitabilitas ini menunjukkan bahwa setiap Rp 100,00 biaya produksi yang dikeluarkan petani mampu menghasilkan keuntungan sebesar Rp 772,00.

\section{Uji One Sample T-Test}

Uji one sampel t-test merupakan uji yang digunakan untuk menguji beda suatu kelompok dengan membandingkannya dengan suatu nilai tesnya. Tingkat keuntungan usahatani alpukat dapat diuji beda dengan membandingkan profitabilitas usaha petani dengan suku bunga bank. Suku bunga bank deposito yang digunakan yaitu Bank BRI sebesar 5,5\%. Berikut merupakan hasil pengujian One Sample T-Test data profitabilitas usahatani alpukat di Kabupaten Semarang:

Tabel 2. Uji One Sample T-Test

\begin{tabular}{lc}
\hline \hline & Nilai \\
\hline Signifikansi & 0,044 \\
Test Value & $5,5 \%$ \\
\hline
\end{tabular}

Sumber: Data Primer Olahan Penelitian, 2017.

Berdasarkan data pada Tabel 2 menyatakan bahwa hasil uji One Sample TTest dengan test value suku bunga deposito sebesar $5,5 \%$ yaitu diperoleh signifikansi 0,044. Hal ini berarti nilai signifikansi lebih kecil dari taraf signifikansi $5 \%$ yaitu $0,044<0,05$, sehingga dapat disimpulkan bahwa usahatani alpukat yang dilakukan oleh petani menghasilkan pendapatan yang menguntungkan.

\section{Analisis Regresi Linier Berganda}

Analisis regresi linier berganda dilakukan untuk mengetahui pengaruh antara variabel-variabel bebas terhadap variabel terikat. Variabel bebas yaitu terdiri dari $\mathrm{X}_{1}$ jumlah produksi, $\mathrm{X}_{2}$ biaya tenaga kerja, $\mathrm{X}_{3}$ biaya pupuk, dan $\mathrm{X}_{4}$ harga jual, sedangkan variabel terikat yaitu $\mathrm{Y}$ pendapatan bersih petani alpukat. Analisis pengaruh ini menggunakan regresi linier berganda dengan uji t dan uji F. Uji t digunakan untuk mengetahui pengaruh secara parsial variabel bebas terhadap variabel terikat dan uji $\mathrm{F}$ digunakan untuk mengetahui pengaruh secara serempak variabel bebas dan variabel terikat. Berdasarkan hasil pengujian diperoleh hasil estimasi regresi sebagai berikut: 
Tabel 3. Hasil Estimasi Regresi

\begin{tabular}{lrrcr}
\hline \hline & Koefisien & Nilai t-hitung & Nilai Signifikansi & \\
\hline $\begin{array}{l}\text { Jumlah } \\
\text { Produksi }\left(\mathrm{X}_{1}\right)\end{array}$ & 0,634 & 10,664 & 0,000 & $*$ \\
$\begin{array}{l}\text { Biaya Tenaga } \\
\text { Kerja }\left(\mathrm{X}_{2}\right)\end{array}$ & 0,222 & 2,475 & 0,018 & $*$ \\
$\begin{array}{l}\text { Biaya Pupuk } \\
\left(\mathrm{X}_{3}\right)\end{array}$ & 0,075 & 0,910 & 0,369 & Ns \\
$\begin{array}{l}\text { Harga Jual } \\
\left(\mathrm{X}_{4}\right)\end{array}$ & 0,346 & 5,521 & 0,000 & $*$ \\
\hline
\end{tabular}

Sumber: Data Olahan Output SPSS, 2017.

Berdasarkan Tabel 3 di atas, maka persamaan regresi yang terbentuk pada uji regresi ini adalah:

$$
Y=\left(-3,035 \cdot 10^{7}\right)+0,634 X_{1}+0,222 X_{2}+0,075 X_{3}+0,346 X_{4}
$$

Berdasarkan persamaan diketahui bahwa:

1. Nilai koefisien regresi variabel jumlah produksi sebesar 0,634 bernilai positif mempunyai arti bahwa jika jumlah produksi bertambah $0,634 \mathrm{Kg}$, maka pendapatan bersih petani alpukat akan meningkat sebesar Rp 0,634.

2. Nilai koefisien regresi variabel biaya tenaga kerja sebesar 0,222 bernilai positif mempunyai arti bahwa jika biaya tenaga kerja bertambah $\operatorname{Rp} 0,222$, maka pendapatan bersih petani alpukat akan meningkat sebesar $\operatorname{Rp} 0,222$.

3. Nilai koefisien regresi variabel harga jual sebesar 0,346 bernilai positif mempunyai arti bahwa jika harga jual meningkat Rp 0,346, maka pendapatan bersih petani alpukat akan meningkat 0,346 .

\section{Uji F}

Parameter yang digunakan dalam uji $\mathrm{F}$ yaitu membandingkan hasil signifikansi $<5 \%$ (taraf siginifikansi). Berikut merupakan hasil pengujian uji $\mathrm{F}$ yang diperoleh:

Tabel 4. Nilai Uji F (Serempak)

\begin{tabular}{lc}
\hline \hline $\mathrm{N}$ & Nilai \\
$\mathrm{df}$ & 40 \\
F-hitung & 4 \\
Signifikansi & 123,347 \\
\hline
\end{tabular}

Sumber: Data Olahan Output SPSS, 2017.

Berdasarkan Tabel 4 menunjukkan bahwa hasil perhitungan uji $\mathrm{F}$, diperoleh nilai F-hitung sebesar 123,347 dengan nilai signifikansi sebesar 0,000 $(<0,05)$. Nilai F-tabel sebesar 2,64 (dari perhitungan $\mathrm{k}=4$, taraf signifikansi= 0,05 dan $\mathrm{df}=\mathrm{n}-\mathrm{k}-1=40-4-1=35$ diperoleh $\mathrm{F}$ tabel 2,64). Sehingga disimpulkan bahwa Sig. 0,000 $<0,05$ dengan demikian $\mathrm{H}_{0}$ ditolak dan $\mathrm{H}_{1}$ diterima, artinya ada pengaruh secara serempak jumlah produksi $\left(\mathrm{X}_{1}\right)$, biaya tenaga kerja $\left(\mathrm{X}_{2}\right)$, biaya pupuk $\left(\mathrm{X}_{3}\right)$ dan harga jual $\left(\mathrm{X}_{4}\right)$ terhadap pendapatan bersih petani alpukat $(\mathrm{Y})$. 
Uji t

Parameter yang digunakan dalam uji $\mathrm{t}$ yaitu membandingkan hasil signifikansi $<5 \%$ (taraf signifikansi). Berdasarkan nilai signifikansi yang terbentuk yaitu diperoleh kesimpulan sebagai berikut:

\section{Pengaruh Jumlah Produksi (X1) terhadap Pendapatan Bersih (Y)}

Berdasarkan hasil perhitungan diperoleh nilai $t$ hitung untuk variabel jumlah produksi $\left(\mathrm{X}_{1}\right)$ adalah sebesar 10,664 dan dengan taraf signifikansi 5\% diperoleh $\mathrm{t}$ tabel sebesar 1,685 (dari perhitungan $\mathrm{df}=40-1=39$ dan taraf signifikansi $=0,05$ diperoleh $\mathrm{t}$-tabel 1,685 ) yang berarti bahwa nilai $\mathrm{t}$ hitung lebih besar dari t tabel yaitu 10,664 > 1,685. Nilai signifikansi t kurang dari 5\% (0,000), menandakan bahwa jumlah produksi $\left(\mathrm{X}_{1}\right)$ mempunyai pengaruh positif dan signifikan terhadap pendapatan bersih petani (Y). Oleh sebab itu, dapat disimpulkan bahwa $\mathrm{H}_{0}$ ditolak dan $\mathrm{H}_{1}$ diterima, sehingga hipotesis yang menyatakan bahwa ada pengaruh jumlah produksi $\left(\mathrm{X}_{1}\right)$ terhadap pendapatan bersih petani dapat diterima.

\section{Pengaruh Biaya Tenaga Kerja $\left(\mathbf{X}_{2}\right)$ terhadap Pendapatan Bersih (Y)}

Berdasarkan hasil perhitungan diperoleh nilai t hitung untuk variabel biaya tenaga kerja $\left(\mathrm{X}_{2}\right)$ adalah sebesar 2,475 dan dengan taraf signifikansi 5\% diperoleh $\mathrm{t}$ tabel sebesar 1,685 (dari perhitungan $\mathrm{df}=40-1=39$ dan taraf signifikansi $=0,05$ diperoleh t-tabel 1,685) yang berarti bahwa nilai t hitung lebih kecil dari t tabel yaitu 2,475 > 1,685. Nilai signifikansi t kurang dari 5\% (0,018), menandakan bahwa biaya tenaga kerja $\left(\mathrm{X}_{2}\right)$ mempunyai pengaruh positif dan signifikan terhadap pendapatan bersih petani (Y). Oleh sebab itu, dapat disimpulkan bahwa $\mathrm{H}_{0}$ ditolak dan $\mathrm{H}_{1}$ diterima, sehingga hipotesis yang menyatakan bahwa ada pengaruh biaya tenaga kerja $\left(\mathrm{X}_{2}\right)$ terhadap pendapatan bersih petani dapat diterima.

\section{Pengaruh Biaya Pupuk $\left(\mathrm{X}_{3}\right)$ terhadap Pendapatan Bersih (Y)}

Berdasarkan hasil perhitungan diperoleh nilai t hitung untuk variabel biaya pupuk $\left(\mathrm{X}_{3}\right)$ adalah sebesar 0,910 dan dengan taraf signifikansi $5 \%$ diperoleh $\mathrm{t}$ tabel sebesar 1,685 (dari perhitungan df $=40-1=39$ dan taraf signifikansi=0,05 diperoleh t-tabel 1,685) yang berarti bahwa nilai t hitung lebih kecil dari t tabel yaitu $0,910<1,685$. Nilai signifikansi t lebih dari $5 \%(0,369)$. menandakan bahwa biaya pupuk $\left(\mathrm{X}_{3}\right)$ tidak mempunyai pengaruh positif dan tidak signifikan terhadap pendapatan bersih petani (Y). Oleh sebab itu, dapat disimpulkan bahwa $\mathrm{H}_{0}$ diterima dan $\mathrm{H}_{1}$ ditolak, sehingga hipotesis yang menyatakan bahwa ada pengaruh biaya pupuk $\left(\mathrm{X}_{3}\right)$ terhadap pendapatan bersih petani tidak terbukti.

\section{Pengaruh Harga Jual $\left(\mathbf{X}_{4}\right)$ terhadap Pendapatan Bersih (Y)}

Berdasarkan hasil perhitungan diperoleh nilai thitung untuk variabel harga jual $\left(\mathrm{X}_{4}\right)$ adalah sebesar 5,521 dan dengan taraf signifikansi 5\% diperoleh $\mathrm{t}$ tabel sebesar 1,685 (dari perhitungan $\mathrm{df}=40-1=39$ dan taraf signifikansi $=0,05$ diperoleh t-tabel 1,685) yang berarti bahwa nilai t hitung lebih besar dari t tabel yaitu 5,521 > 1,685. Nilai signifikansi t kurang dari 5\% (0,000), menandakan bahwa harga jual $\left(\mathrm{X}_{4}\right)$ mempunyai pengaruh positif dan signifikan terhadap pendapatan bersih petani (Y). Oleh sebab itu, dapat disimpulkan bahwa $\mathrm{H}_{0}$ ditolak dan $\mathrm{H}_{1}$ diterima, sehingga hipotesis yang menyatakan bahwa ada pengaruh harga jual $\left(\mathrm{X}_{4}\right)$ terhadap pendapatan bersih petani dapat diterima. 


\section{KESIMPULAN}

Berdasarkan hasil kajian pendapatan usahatani alpukat di Kabupaten Semarang diperoleh bahwa:

1. Rata-rata pendapatan bersih usahatani alpukat yang diusahakan petani sebesar Rp 32.881.705,00, sehingga diperoleh profitabilitas sebesar $7,72 \%$.

2. Pendapatan bersih petani alpukat lebih menguntungkan jika dibandingkan dengan suku bunga bank.

3. Faktor-faktor yang berpengaruh positif terhadap pendapatan bersih petani alpukat yaitu jumlah produksi, biaya tenaga kerja, dan harga jual.

\section{DAFTAR PUSTAKA}

Ambarsari, W., V. D. Y. B. Ismadi dan A. Setiadi. 2014. Analisis Pendapatan dan Profitabilitas Usahatani Padi (Oryza sativa, L.) di Kabupaten Indramayu. J. Agri Wiralodra. 6 (2): $19-27$.

Asra, A. dan A. Prasetyo. 2015. Pengambilan Sampel Dalam Penelitian Survei. Edisi Perdana, PT. Raja Grafindo Persada, Jakarta.

Ekowati, T., H. Setiawan, dan D. Sumarjono. 2014. Usahatani. Universitas Diponegoro, Semarang.

BPS, 2016. Kabupaten Semarang dalam Angka Tahun 2016. BPS Kabupaten Semarang. Kabupaten Semarang.

Lestari, W. D. F., N. D. Naomi, dan M. Najib. 2011. Analisis Pendapatan Dan Titik Impas Usahatani Mentimun (Cucumis sativus L.) di Desa Bangunrejo Kecamatan Tenggarong Seberang Kabupaten Kutai Kartanegara. J. Ekonomi Pembangunan Pertanian. 8 (2): 28 - 32.

Riduwan dan Sunarto. 2012. Pengantar Statistika Untuk Penelitian Pendidikan, Sosial, Ekonomi, Komunikasi dan Bisnis. Alfabeta, Bandung.

Saihani, A. 2012. Analisis Finansial Usahatani Padi Ciherang Pada Sistem Tanam Jajar Legowo di Kecamatan Sungai Tabukan Kabupaten Hulu Sungai Utara Propinsi Kalimantan Selatan. J. Zira'ah. 33 (1): 22 - 27.

Singarimbun, M. Dan S. Effendi. 1989. Metode Penelitian Survai. LP3ES, Jakarta.

Sudjana. 1991. Teknik Analisis Regresi dan Korelasi Bagi Para Peneliti. Tarsito, Bandung. 
Suliyanto. 2011. Ekonometrika Terapan: Teori dan Aplikasi dengan SPSS. CV. Andi Offset, Yogyakarta.

Supranto, J. 2009. Statistik: Teori dan Aplikasi. Edisi Ke-7, Erlangga, Jakarta. 